\title{
Clinical Outcomes of Single-level Posterior Percutaneous Endoscopic Cervical Foraminotomy for Patients with Less Cervical Lordosis
}

\author{
Samuel Jaeyoon Won ${ }^{1}$, Chi Heon Kim ${ }^{2,3,4}$, Chun Kee Chung ${ }^{2,3,4,5}$, Yunhee Choi', Sung Bae Park ${ }^{2,3,4,7}$, \\ Jung Hyeon Moon ${ }^{2,3}$, Won Heo ${ }^{2,3}$, Sung-Mi Kim ${ }^{3,4}$ \\ ${ }^{1}$ Department of Medicine, Seoul National University College of Medicine, Seoul, \\ ${ }^{2}$ Department of Neurosurgery, Seoul National University College of Medicine, Seoul, \\ ${ }^{3}$ Department of Neurosurgery, Seoul National University Hospital, Seoul, \\ ${ }^{4}$ Clinical Research Institute, Seoul National University Hospital, Seoul, \\ ${ }^{5}$ Department of Brain and Cognitive Sciences, Seoul National University College of Natural Sciences, Seoul, \\ ${ }^{6}$ Medical Research Collaborating Center, Seoul National University College of Medicine, Seoul, \\ 'Department of Neurosurgery, Seoul National University Boramae Hospital, Seoul, Korea
}

Corresponding Author: Chi Heon Kim, MD, PhD

Department of Neurosurgery, Seoul National University College of Medicine, 101 Daehak-ro, Jongno-gu, Seoul 03080, Korea

Tel: $+82-2-2072-3398$

Fax: +82-2-744-8459

E-mail: chiheon1@snu.ac.kr

Received: May 1, 2016

Revised: May 12, 2016

Accepted: May 16, 2016
Objective: Posterior percutaneous endoscopic cervical foraminotomy (P-PECF) is a minimally invasive surgical technique for treatment of cervical radiculopathies. Application of P-PECF to patients with preexisting loss of cervical curvature $\left(<10^{\circ}\right)$ is still controversial because violation to facet joint may lead to kyphotic change. Clinical outcomes of P-PECF was analyzed and compared according to preoperative cervical curvature. Methods: In this retrospective nested case-control study, 71 patients who underwent P-PECF due to foraminal soft disc herniation or bony stenosis were reviewed. P-PECF was performed by a single senior surgeon, and surgical methods were as previously described. Visual analogue pain scale on arm (Arm-VAS) was assessed preoperatively and postoperatively $(1,3,6,12$ month and yearly thereafter). All patients were clinically followed for 24.5 \pm 20.0 months. The minimal clinically important difference of the Arm-VAS was set at 2.5. Patients with preoperative cervical curvature $\geq 10^{\circ}$ were included in group I $(n=32)$ and cervical curvature $<10^{\circ}$ or kyphosis were included in the group II $(n=39)$. Results: At the last follow up, $68 / 71$ (96\%) patients showed significant reduction of arm pain (Pre-operation, 7.4 \pm 2.0 ; post-operation, $1.5 \pm 2.0)$ after $1.74 \pm 0.29$ months $(95 \% \mathrm{Cl} ; 1.18-2.31)$. The preoperative cervical curvature did not influence the outcome ( $p=0.4$, T-test) and time to reach the clinical endpoint $(p=0.34$, Cox-logistic regression analysis). Conclusion: P-PECF effectively reduced radicular pain due to foraminal soft disc herniation or stenosis. Preexisting loss of lordosis is not a risk factor for outcomes of P-PECF.

Key Words: Cervical, Endoscope, Kyphosis, Outcome, Pain, Spine, Surgery

\section{INTRODUCTION}

The first line management of cervical radiculopathy is medications or epidural steroid injections that can reduce the pain and inflammation ${ }^{19)}$. If the symptoms persist after these treatments, surgical intervention must be considered ${ }^{5,8,12,14,20)}$. The anterior cervical discectomy and fusion (ACDF) is currently considered as the standard surgical technique ${ }^{1,12,13,27)}$. However, disadvantages of ACDF including limited neck motion, surgical mor- bidity, or degeneration of the adjacent segments have inspired the need for motion preserving and less invasive surgeries ${ }^{4,29,32)}$. Artificial disk replacement may be considered for preserving neck motion, but numerous studies have reported complications such as heterotopic ossification, spontaneous fusion, or mechanical failure ${ }^{12,16,23)}$. Motion preservation surgery such as posterior cervical foraminotomy could be a suitable alternative that can avoid complications related to fusion or instrumentation ${ }^{5,8,20)}$. Nevertheless, there is a concern with open posterior foraminotomy; inevitable damages on facet joints and muscles may shift 
weight-bearing axis anteriorly, thereby worsening cervical lordo$\mathrm{sis}^{8,9,34)}$. Jagannathan et al. suggested that this phenomenon would lead to development of kyphosis after posterior foraminotomy, especially for the patients with preexisting cervical deformity, such as loss of cervical lordosis ${ }^{8)}$. Recent advance in endoscope and tubular retractor has allowed foraminotomy and diskectomy to be performed microscopically with less operation-related trauma ${ }^{14,25)}$. Posterior percutaneous endoscopic cervical foraminotomy (P-PECF) is one of the minimally invasive endoscopic techniques of posterior foraminotomy ${ }^{13,25)}$. Clinical studies and meta-analyses have shown that minimally invasive foraminotomy and/or diskectomy had equal effectiveness to ACDF for patients with radiculopathy ${ }^{1,1214,17,25)}$. Endoscopic techniques especially lessens the neck pain secondary to injuries of muscles compared to the open procedure ${ }^{3,5,6)}$. Nevertheless, there is still a concern with P-PECD that violation of facet joint may still lead to destabilization of the posterior column and subsequent kyphotic change of cervical curvature ${ }^{12,13)}$. However, effective alleviation of radicular symptoms by P-PECD can greatly reduce functional change of spinal curvature due to pain and muscle spasm ${ }^{13,15)}$. If so, kyphotic change or worsening of symptoms may not occur in the patients, even with preexisting loss of lordosis. Application of P-PECF, therefore, may not be contra-indicated for patients with less lordosis preoperatively. Previously we have shown that cervical curvature did not worsen after P-PECF for patients with preoperative cervical lordosis of $<10^{\circ}$ or kyphosis ${ }^{13)}$. There is a need for more evidence on the clinical and radiological outcomes of P-PECF to address this issue. The objective of the present study was to examine association between clinical outcomes of P-PECF and preoperative cervical curvature. We performed nested case-control study between groups of patients with preoperative lordosis of $<10^{\circ}$ and preoperative lordosis of $\geq 10^{\circ}$ as previously defined ${ }^{8)}$.

\section{MATERIALS AND METHODS}

\section{Patients}

The study was approved by the institutional review board at the Seoul National University Hospital (H-1210-078-434). We reviewed 71 consecutive patients $(\mathrm{M}: \mathrm{F}=46: 25$; mean age, 48.9 \pm 10.4 years) who received single level unilateral P-PECF by a single senior surgeon (CHK) between May, 2010 and September, 2015. Magnetic resonance (MR) imaging and computed tomography (CT) scan for diagnosis were taken within 1 month before the surgery. Anterior-posterior and lateral X-rays for postoperative analysis were taken within 2 weeks before the surgery. For the standardized neck position, patients stood up straight and looked ahead during X-ray imaging ${ }^{13)}$. The P-PECD was performed for patients with a radiculopathy due to single-level cervical foraminal soft-disk herniation or foraminal stenosis, and positive Spurling's test ${ }^{11-13,31)}$. The degree of degeneration of the disk was evaluated with T2-weighted sagittal magnetic resonance (MR) imaging as described by Pfirrmann et al. ${ }^{22}$, and grades of I, II and III (inhomogeneous structure of the disk with an intermediate, gray signal intensity with a preserved or slightly decreased disk height) were considered to be acceptable for a P-PECF, if indicated ${ }^{11-14}$. P-PECF was not indicated for patients with pure neck pain, gross cervical instability, symptomatic central disk herniation, central stenosis or myelopathy, severe facet degeneration (joint space narrowing, facet hypertrophy or large osteophyte) ${ }^{21)}$, and ossification of the posterior longitudinal ligament $^{11-13,30)}$. At the preoperative visits, patients completed paper questionnaires to evaluate their symptoms. Neck disability index (NDI; 50 max score being the worst symptoms), and visual analogue scale on neck (neck-VAS; 10 max score being the worst symptoms) and visual analogue scale on arm were used to evaluate patients' symptoms before the operation. After P-PECF, patients were discharged the day after the operation without neck collar and were encouraged to freely move the neck ${ }^{11-13)}$. Patients were scheduled to visit the outpatient clinic at postoperative 1, 3, 6 and 12 months and yearly thereafter. All patients were clinically followed for $24.5 \pm 20.0$ months (median, 20 month; range: 1-62).

\section{Surgical Methods}

The surgical methods were similar to those previously reported $^{11-13,27,28)}$. All operations were performed under general anesthesia. Patients were in the prone position with three-point pin fixation devices with a table mounted holder (Mayfield ${ }^{\mathbb{R}}$ system, Intergra, Painsboro, JN) or craniocervical traction with a Gardner-Wells tongs skeletal fixation system (Fig. 1A) ${ }^{11-13)}$. The neck was held in flexed position in order to widen the interlaminar window with minimized overlapping of facet joints ${ }^{11-13)}$. All 71 operations were performed completely under percutaneous fullendoscopic technique without converting to open surgery (Fig. 1B) ${ }^{13)}$. Skin incision of $8 \mathrm{~mm}$ was made above the medial junction of the inferior and superior facet joint (V-point, Fig. 1C), which was identified with an intraoperative orthogonal fluoroscopic image, the obturator ( $6.9 \mathrm{~mm}$ outer diameter). Working channel (7.9 mm outer diameter) and endoscope (Vertebris ${ }^{\mathbb{R}}$, Richard Wolf $\mathrm{GmbH}$, Knittlingen, Germany) were introduced (Fig. 1D) through the incision ${ }^{11-13)}$. The entire operation was performed under visual control and continuous irrigation with normal saline, which was hung about $1.5 \mathrm{~m}$ above patient ${ }^{11,13,27,28)}$. Once the soft tissue around the $\mathrm{V}$-point is cleared, access window was created by removal of bone around the $\mathrm{V}$-point (Fig. 1C) ${ }^{11-13)}$. Descending lamina, ascending lamina, and facet joint were successively drilled to create a space of 3-4 $\mathrm{mm}$ radius, while the size of the space may vary depending on the size and location of the herniated disc material ${ }^{11-13)}$. Lateral margins of the dura and exiting nerve root were identified after removal of ligamentum flavum. Soft tissues and vessels around nerve root were meticulously coagulated to control bleeding. Ruptured disc fragments were identified from axillar or shoulder of nerve root and were removed in 48 patients. Decompression of nerve root was confirmed by both visualization and palpation from points either inferior or superior to the nerve root ${ }^{11-13)}$. After the operation, 

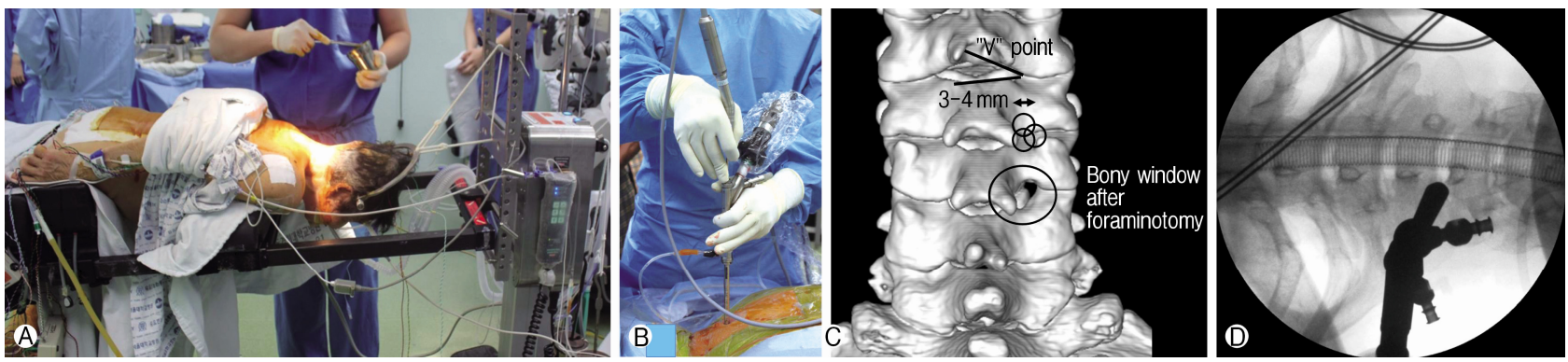

Fig. 1. Surgical procedures. (A) Skeletal fixation with Gardner-well tongue. (B) For right-handed surgeon, the left hand holds endoscope, and the right hand holds instruments such as drill, forceps and punch. (C) Reconstructed 3-D computed tomography scan after operation shows that lamina and facet joint are drilled-out from $\mathrm{V}$-point and the foraminotomy is performed (bony defect inside circle). (D) The endoscope is introduced on the $\mathrm{V}$-point.

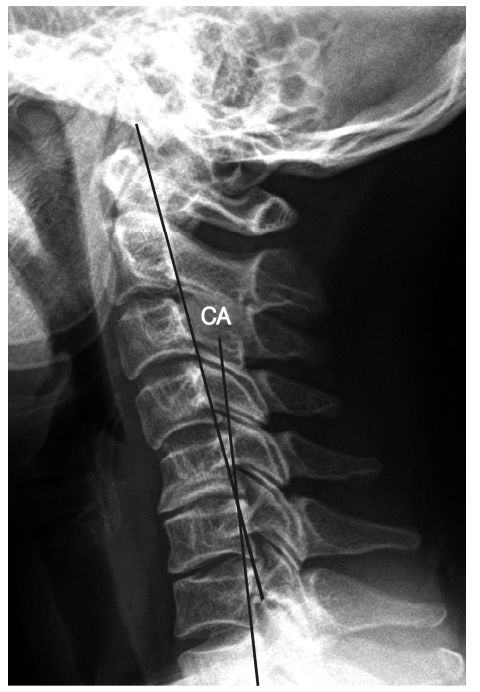

Fig. 2. Measurement of Cervical angle The $\mathrm{C} 2-\mathrm{C} 7$ tangential method measures the angle formed at the intersection of extended tangents drawn at the posterior margin of $\mathrm{C} 2$ and C7 vertebral body.

a closed suction drain was inserted through the working channel in case of epidural bleeding and it was removed the next day ${ }^{11-13)}$.

\section{Radiological Measurements}

Cervical curvature was measured using the $\mathrm{C} 2-\mathrm{C} 7$ tangential method on the lateral X-ray (Fig. 2) by an independent medical student blinded to the clinical information of patients, ${ }^{7,13)}$. Negative value of cenvical curvature indicates lordosis and positive value indicates kyphosis. Measurements were performed with the tools in the picture archiving and communication systems (Marosis, version 5483, Infinitt Healthcare, Seoul, Korea) in 200\% magnified images, which ran in a Microsoft Windows environment (Microsoft Corp., Redmond, WA, USA) ${ }^{10,12,13)}$.

\section{Statistical Analysis}

For data analysis, patients were grouped according to preoperative cervical curvature. Patients with preoperative cervical curvature more lordotic than $-10^{\circ}$ were included in group I $(n=32)$, while patients with cervical curvature less lordotic than

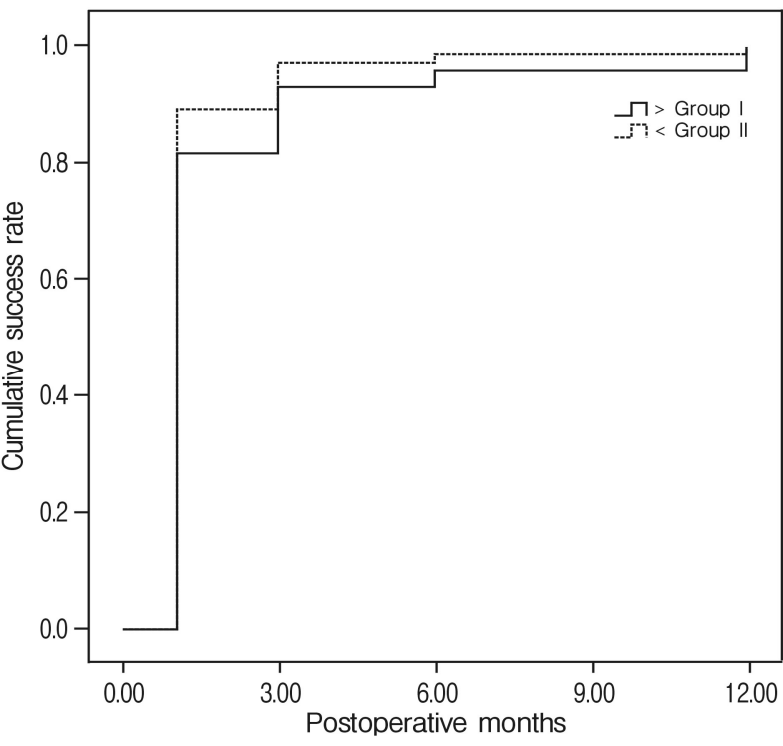

Fig. 3. Cumulative success rate of the operation. $30 / 32$ (94\%) patients with cervical lordosis $\geq 10^{\circ}$ (group I) showed successful outcome at 2.3 \pm 0.6 months $(95 \% \mathrm{Cl}, 1.3-3.5)$. 38/39 (97\%) lordosis $<10^{\circ}$ (group II) showed successful outcome at mean 1.2 \pm 0.1 months $(95 \% \mathrm{Cl}, 0.98-1.32)$ after the surgery. Two groups did not show significant difference in time to reach the clinical endpoint of the surgery $(p=0.34)$.

$-10^{\circ}$ or kyphotic were included in group II $(n=39)$. Student's paired t-test and Chi-square test were used to make comparisons between the groups. To assess successful outcome of the treatment, clinically important change was defined as Arm-VAS $<2.5$, Neck-VAS $<2.5$, and NDI $<7.5$, respectively, in accordance with the previous literature ${ }^{2)}$. Kaplan-Meier analysis was utilized to assess cumulative success rate during follow-up. Cox-logistic regression analysis was performed to assess influence of cervical curvature on clinical outcome. Considered co-variates were age, sex, side, and disease category (soft disc herniation vs. foraminal stenosis). All statistical analyses were completed using SPSS (version 22.0, SPSS, Chicago, Illinois, United States), and statistical significance was defined as $p<0.05$ (two-sided). 
Samuel Jaeyoon Won, et al.

Table 1. The characteristics of patients

\begin{tabular}{|c|c|c|c|c|}
\hline & $\begin{array}{c}\text { Group I } \\
(n=32)\end{array}$ & $\begin{array}{l}\text { Group II } \\
(n=39)\end{array}$ & Total & $p^{-v}$ alue \\
\hline  & $\begin{array}{l}52.4 \pm 9 \\
(31-68)\end{array}$ & $\begin{array}{l}45.9 \pm 10.8 \\
(26-70)\end{array}$ & $\begin{array}{l}48.9 \pm 10.5 \\
(26-70)\end{array}$ & 0.01 \\
\hline $\operatorname{Sex}(M: F)$ & 19:13 & $27: 12$ & $46: 25$ & 0.38 \\
\hline \multicolumn{5}{|l|}{ Level } \\
\hline C3-4 & & 1 & 1 & \\
\hline C4-5 & 3 & 2 & 5 & \\
\hline C5-6 & 10 & 13 & 23 & \\
\hline C6-7 & 15 & 19 & 34 & \\
\hline C7-T1 & 4 & 4 & 8 & \\
\hline Side (R:L) & $9: 23$ & 19:20 & $28: 43$ & 0.77 \\
\hline Soft disc herniation & 22 & 26 & 48 & 0.72 \\
\hline Kyphosis & 0 & 11 & 11 & \\
\hline $\begin{array}{l}\text { Clinical follow-up } \\
\text { (mo) }\end{array}$ & $\begin{array}{l}25 \pm 19 \\
(1-62)\end{array}$ & $\begin{array}{l}24 \pm 21 \\
(1-61)\end{array}$ & $\begin{array}{l}25 \pm 20 \\
(1-62)\end{array}$ & 0.79 \\
\hline $\begin{array}{l}\text { Radiological } \\
\text { follow-up (mo) }\end{array}$ & $\begin{array}{l}9 \pm 13 \\
(0-55)\end{array}$ & $\begin{array}{l}10 \pm 15 \\
(0-54)\end{array}$ & $\begin{array}{l}10 \pm 14 \\
(0-55)\end{array}$ & 0.76 \\
\hline
\end{tabular}

\section{RESULTS}

The characteristics of patients were described in Table 1. At the last follow up, 68/71 (96\%) patients who underwent cervical foraminotomy had significant reduction of arm pain, which was set as the primary endpoint of the surgery $y^{2}$. Preoperative arm-VAS score significantly decreased from $7.4 \pm 2.0$ to $1.5 \pm 2.0(p<0.05)$ at the last follow-up. The successful outcome was reached 1.74 \pm 0.29 months $(95 \% \mathrm{Cl} ; 1.18-2.31)$ after the operation (Fig. 3). Because the patients were followed at pre-determined time points, clinically important change of Arm-VAS was regarded to have occurred between 1 and 3 month follow ups ${ }^{15}$. Postoperative arm-VAS of group I and group II were 1.3 \pm 1.6 and 1.7 \pm 2.2 , respectively, with no significant difference $(p=0.4)$. Mean time to reach the clinical endpoint for the two groups were not significantly different (group I vs. group II; $2.3 \pm 0.6$ vs. $1.2 \pm 0.1$ months, $p=0.34$ ). As the result of Cox-logistic regression analysis, there was no prognostic factor for outcome of the surgery ( $p$-value of age, sex, side and disease category: 0.80, 0.83, 0.38 and 0.64 , respectively). Patients without improvement of pain did not undergo further surgery. Although 2 out of 68 improved patients experienced recurrence of arm pain at 36 and 54 months, respectively, the recurred pain was controlled with epidural steroid injections.

Neck-VAS and NDI also significantly decreased for group I and group II (Table 2). 67 out of 71 (94\%) patients reached the clinical endpoint for $\mathrm{NDI}$ after $2.32 \pm 0.39$ months $(95 \% \mathrm{Cl}$, 1.55-3.08), while 66/71 (93\%) patients reached the clinical endpoint for neck-VAS after $4.10 \pm 0.90$ months $(95 \% \mathrm{Cl}, 2.35-5.86)$. Group I and group II showed no significant difference on NeckVAS and NDI scores (Table 2 and Fig. 4).
Table 2. Clinical outcomes according to the group

\begin{tabular}{|c|c|c|c|c|c|}
\hline & & & Mean & SD & p-value \\
\hline \multirow[t]{4}{*}{ NDI } & preop & Group I & 23.2 & 8.3 & 0.8 \\
\hline & & Group II & 22.7 & 8.0 & \\
\hline & final & Group I & 4.2 & 5.3 & 0.9 \\
\hline & & Group II & 4.1 & 4.3 & \\
\hline \multirow[t]{4}{*}{ VAS-neck } & preop & Group I & 5.3 & 2.4 & 1.0 \\
\hline & & Group II & 5.3 & 2.9 & \\
\hline & final & Group I & 1.3 & 1.8 & 0.9 \\
\hline & & Group II & 1.3 & 1.6 & \\
\hline \multirow[t]{4}{*}{ VAS-arm } & preop & Group I & 7.3 & 2.0 & 0.9 \\
\hline & & Group II & 7.4 & 2.0 & \\
\hline & final & Group I & 1.3 & 1.6 & 0.4 \\
\hline & & Group II & 1.7 & 2.2 & \\
\hline
\end{tabular}

${ }^{*}$ Comparison between group I and II

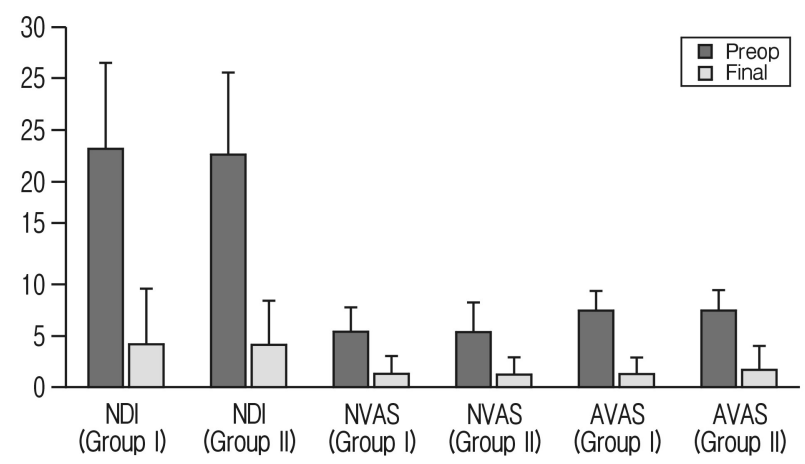

Fig. 4. Comparison of clinical outcomes between the two groups. Group I: preoperative cervical lordosis $\geq 10^{\circ}$, Group II: preoperative cervical lordosis $<10^{\circ}$. Preoperative Neck disability index (NDI), neck pain (NVAS) and arm pain (AVAS) were not different between the two groups. The clinical parameters were significantly decreased in both groups without significant difference between groups ( $p>0.05)$

Complication occurred in 3 patients. Postoperatively, C6 nerve palsy occurred in 1 patient after operation at C5-6. Manual motor power was IIIN in elbow flexion. The weakness was resolved with rehabilitation therapy 6 months after the surgery. Transient dysesthesia occurred in 2 patients (due to thermal injury in one and dural tear in the other), which persisted less than 1 week without sequelae $\mathrm{e}^{11-13)}$

\section{Case}

A 42-year-old female patient presented with right neck pain shooting down to forearm and wrist, which started 6 month ago. The pain was intractable to medications or epidural injections. Her NDI, neck-VAS, and arm-VAS were 35/50, 10/10, and 10/10, respectively. Preoperative lateral $X$-ray showed kyphotic cervical curvature (3.8 ) (Fig. 5A). Preoperative T2-weighted MR images showed that right $\mathrm{C} 7$ nerve root was compressed by 

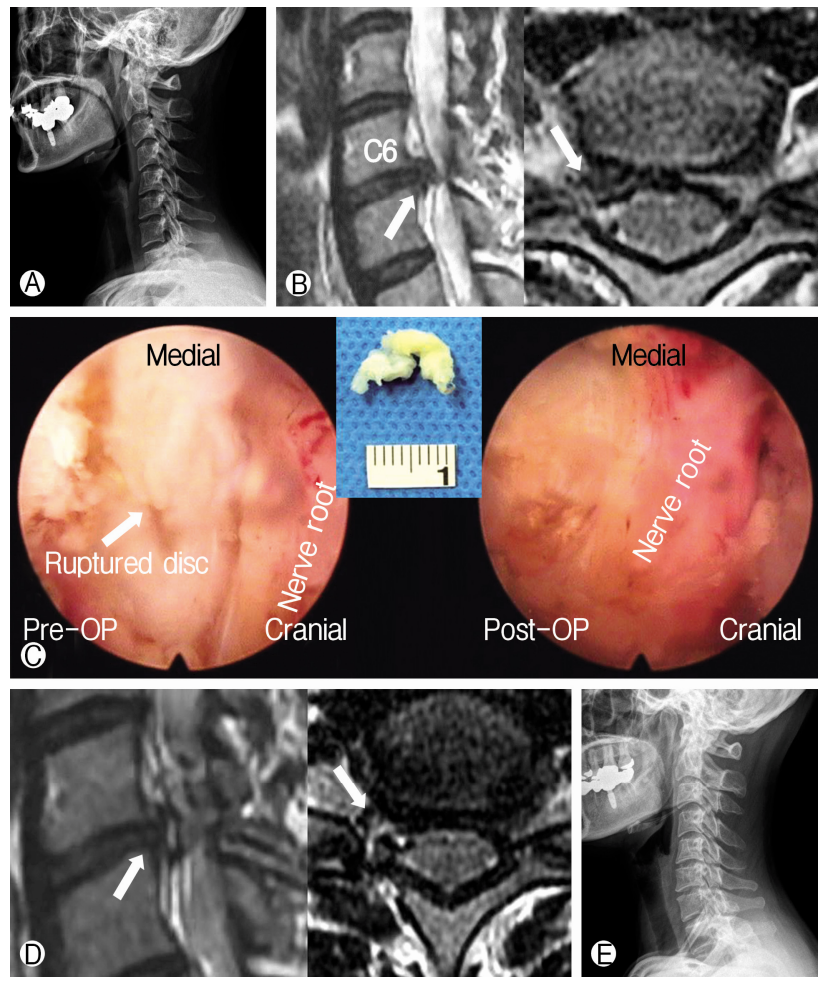

Fig. 5. Case. (A) Preoperative $X$-ray shows cervical angle of $+3.8^{\circ}$ (kyphosis). (B) Preoperative sagittal and axial magnetic resonance (MR) images show right side soft disc herniation at C6-7 (Arrows). (C) Intraoperative photo shows ruptured disc compressing nerve roots at the axilla (left). Ruptured disc was removed (middle) and decompression is confirmed (right). Both superior and inferior parts of the nerve roots were decompressed. (D) Postoperative sagittal and axial magnetic resonance (MR) images show that the right side soft disc herniation at C6-7 has been removed (Arrows). (E) X-ray taken 12 month after the operation shows cervical angle of $-13.16^{\circ}$ (lordosis).

a herniated disc material (Fig. 5B). P-PECF with discectomy was performed at C6-7 (Fig. 5C). Decompression of nerve roots were confirmed on MR images (Fig. 5D). At the 12-month follow up visit, she reported NDI, neck VAS, and arm VAS to be 0/50, $0 / 10$, and 0/10, respectively. Patient's 1-year postoperative $x$-ray image showed recovery of cervical lordosis $\left(-13.16^{\circ}\right)$ (Fig. 5E).

\section{DISCUSSION}

Full endoscopic cervical foraminotomy and diskectomy have been gaining evidence as an alternative treatment for patients with unilateral radiculopathy due to soft disc herniation or foraminal stenosis ${ }^{11-14,20,27,28,33)}$. The objective of the study was to examine clinical outcomes of post-PECF and compare the outcomes between patients with preserved lordosis $\left(\geq 10^{\circ}\right)$ and patients with less lordosis $\left(<10^{\circ}\right)$. Results from our study were similar to previous findings ${ }^{13,27,28)}$; more than $80 \%$ of the patients experienced successful reduction of arm pain between 1 month and 3 months postoperatively (mean, $1.74 \pm 0.29$ months) (pre-op arm-VAS: $7.4 \pm 2.0$; post-op arm VAS: $1.5 \pm 2.0 ; p<0.05$ ). By the last follow up, $96 \%$ of patients reported no or negligible arm pain. Similarly, clinical endpoint of NDI and Neck-VAS was reached between 1 and 3 months after the surgery for all patients.

\section{Posterior percutaneous endoscopic cervical forami- notomy (P-PECF)}

Posterior cervical foraminotomy is surgical technique that partially removes lamina and facet joint to widen neural foramen and decompress nerve roots ${ }^{5,24)}$. This procedure is usually indicated for patients with unilateral radiculopathy. Retrospective propensity-score matched study showed that the reoperation rate of posterior foraminotomy was comparable to $\mathrm{ACDF}^{18)}$. Previous studies showed favorable results with minimally invasive cervical foraminotomy compared to open foraminotomy ${ }^{12-14,24,27)}$. In this regards, P-PECF may be an acceptable treatment for patients with narrowing of unilateral neural foramen either by soft disc herniation or bony stenosis ${ }^{1,17,25)}$. However, the major issue of posterior foraminotomy is postoperative progression to cervical kyphosis, and anterior instrumented correction has been recommended for this reason. Even with the microscopic approach $^{13,25)}$, P-PECF may damage facet joint to destabilize the anterior-posterior balance of spinal neural arch complex ${ }^{3,8)}$. Nevertheless, outcomes of P-PECF may be different from open foraminotomy, because P-PECF still has less surgical trauma on facet joint and especially spine muscles ${ }^{8,12,13,25)}$. Therefore, P-PECF resolves the issue of open foraminotomy regarding persistent neck pain secondary to muscle tear ${ }^{3,5,6)}$. The data from this study also supports P-PECF can effectively resolve neck pain (pre-op vs. post-op NDI: $23.0 \pm 7.9$ vs $4.3 \pm 5.4$, $p<0.05$; pre-op vs. post-op Neck-VAS: $5.3 \pm 2.7$ vs. $1.2 \pm 1.6 ; p<0.05$ ). Functional change of cervical curvature due to neck pain is less likely to occur after P-PECF, and patients may not be as vulnerable to progressive angulation as in open foraminotomy ${ }^{13)}$. Hence, preexisting loss of lordosis $\left(<10^{\circ}\right)$ may not always be a contra-indication for $\mathrm{P}^{\mathrm{PECF}}{ }^{8)}$. We have previously shown that cervical curvature did not worsen after P-PECD for patients with preoperative cervical lordosis of $<10^{\circ}$ or kyphosis ${ }^{13)}$. In this study, we examined the topic of whether cervical curvature would influence clinical outcomes of endoscopic foraminotomy. 96\% of patients reported successful reduction of clinical symptoms (represented in Arm-VAS, NDI and Neck-VAS), and the clinical outcomes were not different between patients with lordosis $\geq 10^{\circ}$ and patients with lordosis $<10^{\circ}$ (Table 2). This finding is along the same line with our previous study, which concluded that cervical curvature did not worsen for patients with lordosis $<10^{\circ 13)}$. Based on the results of both studies, we suggest that preoperative cervical curvature is not related to clinical outcomes of endoscopic cervical foraminotomy. Nevertheless, the surgical damage to facet joint and musculature may offset the temporary improvement, and neck or arm pain may worsen with time. A long-term follow-up observation is necessary to find the trade-off point between natural return of curvature and aggravation of curvature because of surgical trauma, which 
may not be $-10^{\circ}$ of cervical curvature.

\section{Limitation of the present study}

This study had several limitations. First, the study is susceptible to selection bias because of its retrospective design. The number of patients included in this study is small and there may be type I statistical error. Secondly, functional change of cervical curvature was not clearly defined. We applied P-PECF for patient with predominant arm pain when degenerative change at the disc and facet joint were not severe. However, prognostic factor for return of the normal curvature is still unclear. This topic will be examined in our next study. Moreover, the follow-up periods were not uniform across the patients. A larger prospective study is necessary to find out ideal surgical candidate for P-PECF. Third, the P-PECF is not a wide-spread surgical procedure and there was limitation of generalizability. Endoscopic technique has a high learning curve that requires considerable amount of training and it may depend on expertise of a surgeon ${ }^{3,12,26)}$. Finally, radiological outcomes were not included in the present study. Clinical improvement does not always indicate successful surgical outcome, and the assessment should be supported with radiological data. Radiological analysis will be included in our prospective study. Nonetheless, the present study showed feasibility of applying P-PECD to the patients who have less cervical lordosis.

\section{CONCLUSION}

P-PECF is an effective surgical technique for treating radicular pain in patients with foraminal soft disc herniation or stenosis. Clinical outcomes of P-PECF was independent of preoperative cervical curvature. Therefore, we suggest that P-PECF may be a good surgical option to resolve radicular pain symptoms, even for patients with loss of cervical curvature. Long-term radiological and clinical outcome analyses are required to further investigate on the application of P-PECD to patients with less cervical lordosis.

\section{ACKNOWLEDGMENTS}

This work was supported by Grant No. 0420153090 (2015-0987) from the Seoul National University Hospital. The second author (CHK) is a consultant of Richard Wolf $\mathrm{GmbH}$. CKC and SBP are users of the endoscopic equipment of Richard Wolf $\mathrm{GmbH}$. The other authors declare no conflict of interest concerning the materials or methods used in this study or the findings described in this paper. This study was approved by the institutional review board at the Seoul National University Hospital $(\mathrm{H}-1210-078-434)$.

\section{REFERENCES}

1. Birkenmaier C, Komp M, Leu HF, Wegener B, Ruetten S: The current state of endoscopic disc surgery: review of controlled studies comparing full-endoscopic procedures for disc herniations to standard procedures. Pain Physician 16:335-344, 2013

2. Carreon LY, Glassman SD, Campbell MJ, Anderson PA: Neck Disability Index, short form-36 physical component summary, and pain scales for neck and arm pain: the minimum clinically important difference and substantial clinical benefit after cervical spine fusion. Spine J 10:469-474, 2010

3. Chang JC, Park HK, Choi SK: Posterior cervical inclinatory foraminotomy for spondylotic radiculopathy preliminary. J Korean Neurosurg Soc 49:308-313, 2011

4. Cho SK, Riew KD: Adjacent segment disease following cervical spine surgery. J Am Acad Orthop Surg 21:3-11, 2013

5. Fehlings MG, Gray RJ: Posterior cervical foraminotomy for the treatment of cervical radiculopathy. J Neurosurg Spine 10:343344; author reply 344-346, 2009

6. Grieve JP, Kitchen ND, Moore AJ, Marsh HT: Results of posterior cervical foraminotomy for treatment of cervical spondylitic radiculopathy. Br J Neurosurg 14:40-43, 2000

7. Harrison DE, Harrison DD, Cailliet R, Troyanovich SJ, Janik TJ, Holland B: Cobb method or Harrison posterior tangent method: which to choose for lateral cervical radiographic analysis. Spine (Phila Pa 1976) 25:2072-2078, 2000

8. Jagannathan J, Sherman JH, Szabo T, Shaffrey CI, Jane JA: The posterior cervical foraminotomy in the treatment of cervical discl osteophyte disease: a single-surgeon experience with a minimum of 5 years' clinical and radiographic follow-up. J Neurosurg Spine 10:347-356, 2009

9. Kaptain GJ, Simmons NE, Replogle RE, Pobereskin L: Incidence and outcome of kyphotic deformity following laminectomy for cervical spondylotic myelopathy. J Neurosurg 93:199-204, 2000

10. Kim CH, Chung CK, Hong HS, Kim EH, Kim MJ, Park BJ: Validation of a simple computerized tool for measuring spinal and pelvic parameters. J Neurosurg Spine 16:154-162, 2012

11. Kim CH, Chung CK, Kim HJ, Jahng TA, Kim DG: Early outcome of posterior cervical endoscopic discectomy: an alternative treatment choice for physically/socially active patients. J Korean Med Sci 24:302-306, 2009

12. Kim CH, Kim KT, Chung CK, Park SB, Yang SH, Kim SM, et al: Minimally invasive cervical foraminotomy and diskectomy for laterally located soft disk herniation. Eur Spine J 24:30053012, 2015

13. Kim $\mathrm{CH}$, Shin $\mathrm{KH}$, Chung $\mathrm{CK}$, Park SB, Kim JH: Changes in cervical sagittal alignment after single-level posterior percutaneous endoscopic cervical diskectomy. Global Spine J 5:31-38, 2015

14. Kim KT, Kim YB: Comparison between open procedure and tubular retractor assisted procedure for cervical radiculopathy: results of a randomized controlled study. J Korean Med Sci 24: 649-653, 2009

15. Kim R, Kim RH, Kim CH, Choi Y, Hong HS, Park SB, et al: The Incidence and Risk Factors for Lumbar or Sciatic Scoliosis in Lumbar Disc Herniation and the Outcomes after Percutaneous Endoscopic Discectomy. Pain Physician 18:555-564, 2015

16. Lee SE, Chung CK, Jahng TA: Early development and progression of heterotopic ossification in cervical total disc replacement. J Neurosurg Spine 16:31-36, 2012

17. Li XC, Zhong CF, Deng GB, Liang RW, Huang CM: Full-Endoscopic Procedures Versus Traditional Discectomy Surgery for Discectomy: A Systematic Review and Meta-analysis of Current 
Global Clinical Trials. Pain Physician 19:103-118, 2016

18. Lubelski D, Healy AT, Silverstein MP, Abdullah KG, Thompson $\mathrm{NR}$, Riew KD, et al: Reoperation rates after anterior cervical discectomy and fusion versus posterior cervical foraminotomy: a propensity-matched analysis. Spine J 15:1277-1283, 2015

19. Nordin M, Carragee EJ, Hogg-Johnson S, Weiner SS, Hurwitz EL, Peloso PM, et al: Assessment of neck pain and its associated disorders: results of the Bone and Joint Decade 2000-2010 Task Force on Neck Pain and Its Associated Disorders. J Manipulative Physiol Ther 32:S117-140, 2009

20. O'Toole JE, Sheikh H, Eichholz KM, Fessler RG, Perez-Cruet MJ: Endoscopic posterior cervical foraminotomy and discectomy. Neurosurg Clin N Am 17:411-422, 2006

21. Park MS, Lee YB, Moon SH, Lee HM, Kim TH, Oh JB, et al: Facet joint degeneration of the cervical spine: a computed tomographic analysis of 320 patients. Spine (Phila Pa 1976) 39:E713718, 2014

22. Pfirrmann CW, Metzdorf A, Zanetti M, Hodler J, Boos N: Magnetic resonance classification of lumbar intervertebral disc degeneration. Spine (Phila Pa 1976) 26:1873-1878, 2001

23. Richards O, Choi D, Timothy J: Cervical arthroplasty: the beginning, the middle, the end? Br J Neurosurg 26:2-6, 2012

24. Riew KD, Cheng I, Pimenta L, Taylor B: Posterior cervical spine surgery for radiculopathy. Neurosurgery 60:S57-63, 2007

25. Ruetten S, Komp M, Merk H, Godolias G: Full-endoscopic anterior decompression versus conventional anterior decompression and fusion in cervical disc herniations. Int Orthop 33:1677-1682, 2009

26. Ruetten S, Komp M, Merk H, Godolias G: Full-endoscopic cervical posterior foraminotomy for the operation of lateral disc herniations using 5.9-mm endoscopes - A prospective, randomized, controlled study. Spine 33:940-948, 2008

27. Ruetten S, Komp M, Merk H, Godolias G: Full-endoscopic cervical posterior foraminotomy for the operation of lateral disc herniations using 5.9-mm endoscopes: a prospective, randomized, controlled study. Spine (Phila Pa 1976) 33:940-948, 2008

28. Ruetten S, Komp M, Merk H, Godolias G: A new full-endoscopic technique for cervical posterior foraminotomy in the treatment of lateral disc herniations using 6.9-mm endoscopes: prospective 2-year results of 87 patients. Minim Invasive Neurosurg 50: 219-226, 2007

29. Seth AK, Puri P, Chandra A: Role of ultrathin transnasal esophagogastroduodenoscopy: experience with 50 patients. Indian J Gastroenterol, 2010

30. Skovrlj B, Gologorsky Y, Haque R, Fessler RG, Qureshi SA: Complications, outcomes, and need for fusion after minimally invasive posterior cervical foraminotomy and microdiscectomy. Spine J 14:2405-2411, 2014

31. Tong HC, Haig AJ, Yamakawa K: The Spurling test and cervical radiculopathy. Spine (Phila Pa 1976) 27:156-159, 2002

32. Wright RA: Upper-esophageal perforation with a flexible endoscope secondary to cervical osteophytes. Dig Dis Sci 25:66-68, 1980

33. Yang JS, Chu L, Chen L, Chen F, Ke ZY, Deng ZL: Anterior or posterior approach of full-endoscopic cervical discectomy for cervical intervertebral disc herniation? A comparative cohort study. Spine (Phila Pa 1976) 39:1743-1750, 2014

34. Zdeblick TA, Zou D, Warden KE, McCabe R, Kunz D, Vanderby R: Cervical stability after foraminotomy. A biomechanical in vitro analysis. J Bone Joint Surg Am 74:22-27, 1992 